\title{
OPTICAL SPECTRA OF NEODYMIUM AND EUROPIUM TUNGSTATES AND MOLYBDATES
}

\author{
L. Macalik, J. Hanuza \\ W. Trzebiatowski Institute for Low Temperatures and Structure Research \\ Polish Academy of Sciences \\ P.O. Box 937, 50-950 Wrocław, Poland
}

AND J. LEGENDZIEWICZ

Institute of Chemistry, University of Wrocław, F. Joliot-Curie 14, 50-383 Wrocław

\begin{abstract}
Absorption and excitation spectra of lanthanides molybdates and tungstates were measured and analyzed. Probabilities of electronic transitions were analysed on the basis of the Judd-Ofelt theory. The significant differences of intensities were observed. Those differences could result from the symmetry changes, cooperative effects and electron-phonon interaction. The elucidation of intensities given by separate mechanisms needs further investigation.

PACS numbers: 33.60.Cv, 33.50.Dq, 33.70.Ca, 78.20.Dj
\end{abstract}

\section{Introduction}

Recently a big effort was made to explain the nature of optical properties of lanthanides tungstates and molybdates. The main interest of these investigations concerns the energy transfer and energy migration in one-, two- and three-dimensional systems; with one and more site symmetry positions [1-3].

The single crystals of neodymium tungstates and molybdates of types $\mathrm{KLn}\left(\mathrm{WO}_{4}\right)_{2}$ and $\mathrm{KLn}\left(\mathrm{MoO}_{4}\right)_{2}$ and doped $\mathrm{KY}\left(\mathrm{MoO}_{4}\right)_{2}: \mathrm{Ln}$ are especially interesting for the reason of their applications [4]. Numerous studies have been made on vibronic transition associated with $4 f-4 f$ transitions of rare earth ions in crystals. The vibronic transitions observed in optical spectra reflect electron-lattice interaction, which also causes variations of nonradiative transitions types [5]. These studies can explain what types of phonons are coupled in the vibronic transitions and what sort of mechanism can explain their intensities [6].

On the other hand, the dimensionality of the systems is an important parameter of the relaxation dynamics of metal ions in solids which imposes the restriction on ion-ion interaction. These types of investigations are the newest and of great importance in explanation of both the concentration dependence of intensities of optical lines and the structure of optical lines [7]. 
In this paper we would like to explain: (a) the differences in electronic transition intensities of neodymium tungstates and molybdates on the basis of absorption spectra and (b) the differences in vibronic structures of optical bands in both the types of crystals, basing on the excitation spectra at $77 \mathrm{~K}$ and absorption spectra at $5 \mathrm{~K}$.

\section{Experimental}

The single crystals of $\mathrm{KLn}\left(\mathrm{MoO}_{4}\right)_{2}$ and $\mathrm{KLn}\left(\mathrm{WO}_{4}\right)_{2}$ were grown from using the method described by Klevtsova et al. [8].

The absorption spectra at 300 and $5 \mathrm{~K}$ were measured using Cary-Varian 5 spectrophotometer. The intensity analysis was performed according to the procedure described in Ref. [9].

Excitation spectra were detected by SPF-500 SOPRA spectrofluorometer. The analysis of vibronic sidebands was performed on the basis of IR and Raman spectra [10].

\section{Results and discussion}

Figures 1-3 show the absorption spectra of neodymium tungstate and molybdate at 300 and $5 \mathrm{~K}$ and excitation spectra of europium single crystals at $77 \mathrm{~K}$. In both the cases the complex structure of the bands is remarkable, as well as the significant differences in their intensities mainly for transitions observed in absorption spectra. Besides main electronic lines, rich vibronic structure of bands is observed.

Crystallographic data for monoclinic tungstates and molybdates indicate complex polymeric structure of the investigated single crystals. From X-ray analysis and IR and Raman spectra Klevtsova and Volkova concluded that two main classes were presented in the case of tungstates [11]. In the former europium compound crystallized creating dimeric subunits of $\mathrm{W}_{2} \mathrm{O}_{10}$ types, while in the latter one, neodymium formed subunits of $\mathrm{W}_{4} \mathrm{O}_{16}^{8-}$ type with two nonequivalent $\mathrm{W}$ sites. In this way the sandwich layer structure is composed of periodical $\mathrm{LnO}_{8}$ and $\mathrm{KO}_{12}$ repited polyhedra. Those differences in the crystal structure are reflected in IR and Raman spectra $[10,12]$.

In the case of molybdates of series of lanthanides some small differences can be found. Neodymium molybdate plays an intermediate role in this series, the probable structure containing separate tetrahedra of $\mathrm{MO}_{4}$ units exists, while europium seems to crystallize in dimeric type structure. In both types of structures $\mathrm{LnO}_{8}$ polyhedra are formed with only little differences in their symmetry distortion.

What effect, if any, of these polymeric structures is observed in the electron spectroscopy of the systems under investigation? In Table I there are compiled the oscillator strength values and the Judd-Ofelt parameters for $\mathrm{KNd}\left(\mathrm{MoO}_{4}\right)_{2}$ and $\mathrm{KLn}\left(\mathrm{WO}_{4}\right)_{2}$ single crystals. The significant differences are observed in the values of oscillator strengths and $\tau_{\lambda}$ parameters for neodymium tungstate and molybdate. On the other hand, all the oscillator strength values are drastically 

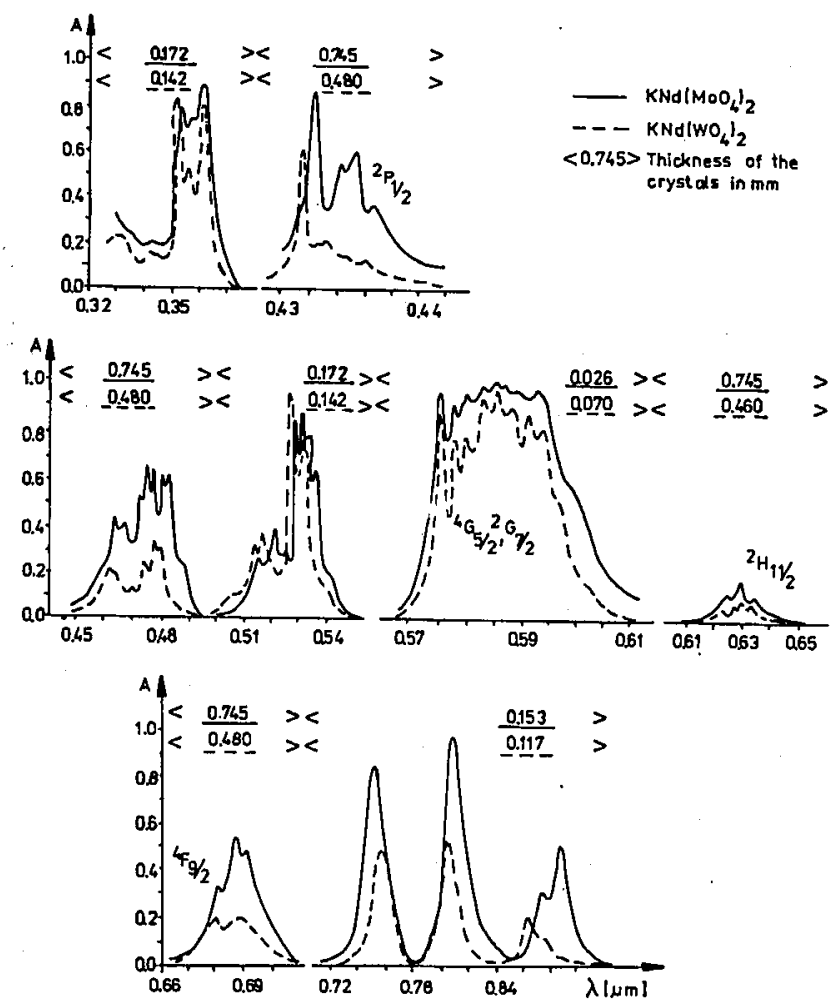

Fig. 1. Absorption spectra of neodymium tungstate and molybdate at $300 \mathrm{~K}$.

increased compared to those observed in the spectra of lanthanide aquoion and other lanthanide compounds with dimeric or polymeric structure [13].

What are the factors which can affect the intensities of electronic transition for the same ion? They are: symmetry, polarizability and, connected with covalency, vibronic coupling and ion-pairs interaction. Judging from the available $\mathrm{X}$-ray and IR data for two types of compounds of tungstates and molybdates, the site symmetry of $\mathrm{Nd}^{3+}$ ion changes from $C_{2}$ for the former to $C_{3}$ for the latter. Such changes of symmetry cannot explain the drastical changes in intensities.

Similar changes of symmetry for the set of lanthanide polymeric carboxylates did not follow the drastical differences in intensities [13]. Moreover, the intensities of carboxylates are four or three times lower. Let us consider the $\mathrm{Ln}-\mathrm{O}$ bonding lengths. In dimeric carboxylates $\mathrm{Nd}_{2} \mathrm{Ala}_{2}\left(\mathrm{H}_{2} \mathrm{O}\right)_{4}$ they are equal to 2.491 for $\mathrm{Nd}-\mathrm{O}_{\mathrm{WO}_{4}^{2-}} \approx 2.48$ whereas $P_{\exp }$ for ${ }^{4} I_{9 / 2} \rightarrow{ }^{4} G_{5 / 2},{ }^{2} G_{7 / 2}$ are equal to $1237 \times 10^{-8}$ and $3885 \times 10^{-8}$, respectively (Table I). The intensities of ${ }^{4} I_{9 / 2} \rightarrow{ }^{4} G_{5 / 2},{ }^{2} G_{7 / 2}$ transitions in the neodymium tungstate spectra are comparable to those observed in DMF solution of lanthanide nitrates [9], explained by polarizability mechanism of Mason [14], and are little higher than those found for lanthanide nitrate [15]. 

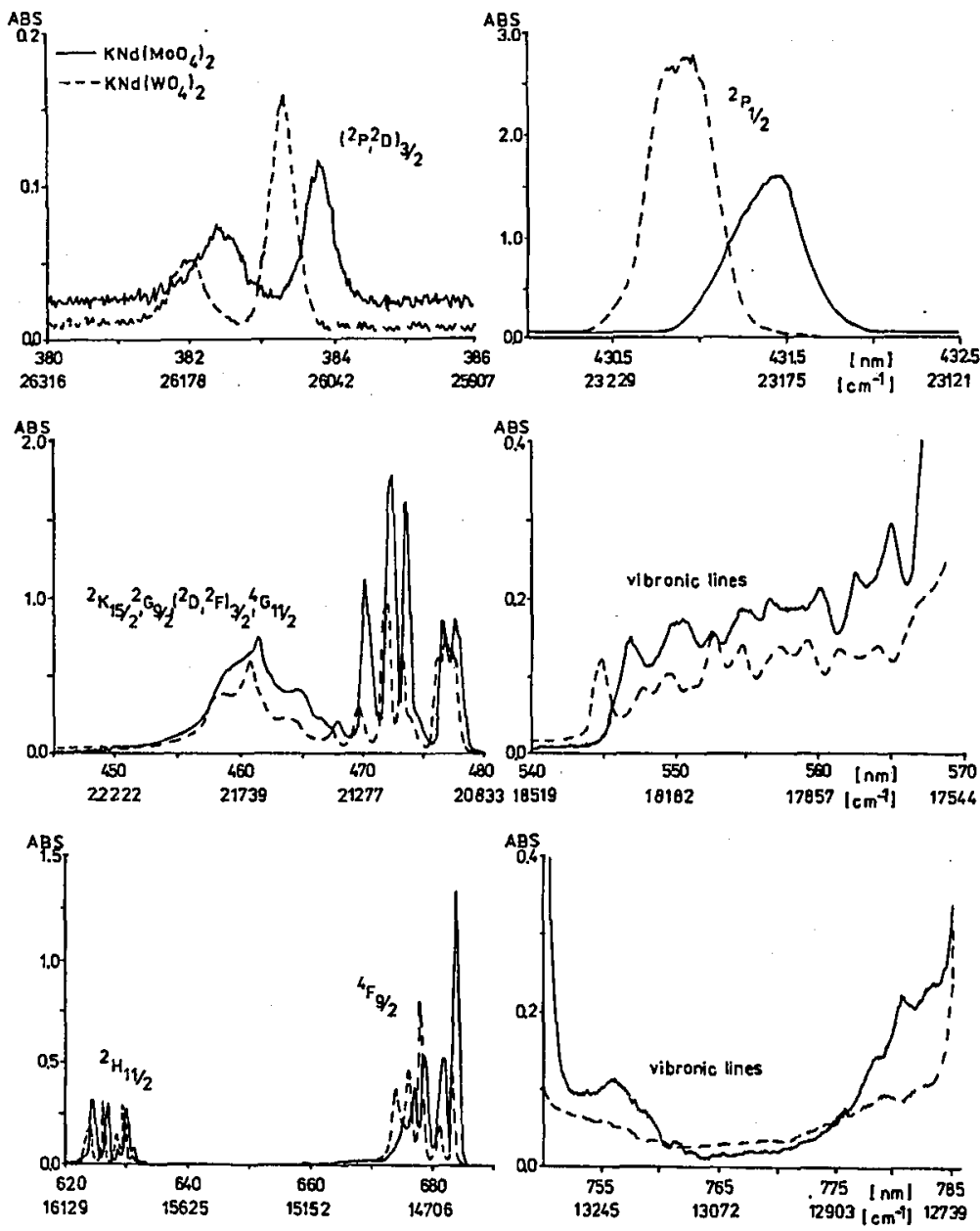

Fig. 2. Absorption spectra of neodymium tungstate and molybdate at $5 \mathrm{~K}$.

To our knowledge, however, such high intensities as observed in molybdates have not been observed up to now in solids. This enhancement of intensities could be a result of different polarizability of tetrameric and separated $\mathrm{MO}_{4}^{2-}$ structures. It can lead to the change in intensities of hypersensitive transition of $\mathrm{Nd}^{3+}$ ion.

Moreover, external vibrational mode attributed to the translational and rotational motions of the unit cell differs significantly for two types of compounds. The relative intensities of internal vibration at $600-800 \mathrm{~cm}^{-1}$ to those at $\approx 400 \mathrm{~cm}^{-1}$ increase for molybdate. These effects must influence the electron-phonon coupling of the systems under investigation. An additional cooperative interaction appears between lanthanide ion pairs composed by two $\mathrm{LnO}_{8}$ polyhedra in tungstate, giving very short $\mathrm{Nd}-\mathrm{Nd}$ distance $(=4.21 \AA)-$ which is much shorter than that 

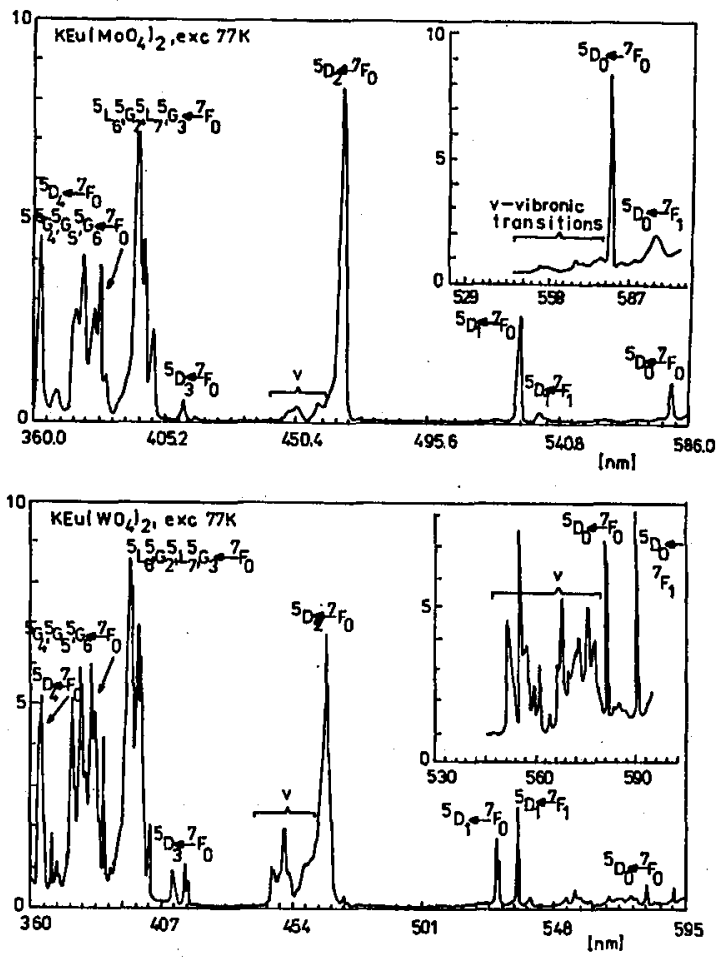

Fig. 3. Excitation spectra of europium single crystals at $77 \mathrm{~K}$.

in dimeric $\mathrm{Ln}_{2} \mathrm{Ala}_{2}\left(\mathrm{H}_{2} \mathrm{O}\right)_{4}$ carboxylate, where ion-pair interaction was stated. Ion-pair interaction could be produced by exchange interaction which varies according to $\exp [-2 R / L]$, where $L$ is the effective ion radius of the rare earth ion and operates only over short distances. Additional interaction can appear through the anion intermediary by superexchange interaction. These interactions can lead to an increase in intensities as well. Now we could not distinguish the intensities given by different mechanisms - it needs further investigation of the diluted systems. Similarly, at this moment Nd-Nd distance in the molybdate is not available, thus it is difficult to elucidate particular mechanisms and participations in overall intensity caused by them.

Coupling of two neodymium ions in dimer yields inhomogeneous broadening of optical lines. High resolution measurement performed at $5 \mathrm{~K}$ leads to broadening of the band corresponding to ${ }^{4} I_{9 / 2} \rightarrow{ }^{2} P_{1 / 2}$ transition (half-width $\approx 26 \mathrm{~cm}^{-1}$ ) in both the single crystals. Similar shapes of optical lines were observed in two types of neodymium dimers with DL-alanine and L-isoleucine, confirming thus the relation between dimeric structure and spectroscopy parameters close to the pseudodisordered effect.

Electron-phonon coupling is quite well observable at $5 \mathrm{~K}$ in high spectral region of electronic transitions, obeying the selection rule $\Delta J=2,0$ as well as 
TABLE I

The experimental $\left(P_{\exp } \times 10^{8}\right)$ and calculated $\left(P_{\mathrm{cal}} \times 10^{8}\right)$ oscillator strength values of $f-f$ transitions and the $\tau_{\lambda}$ parameters.

\begin{tabular}{l|r|r|r|r}
\hline \multirow{2}{*}{ Term } & \multicolumn{2}{|c|}{$\mathrm{KNd}\left(\mathrm{MoO}_{4}\right)_{2}$} & \multicolumn{2}{c}{$\mathrm{KNd}\left(\mathrm{WO}_{4}\right)_{2}$} \\
\cline { 2 - 5 } & \multicolumn{1}{|c|}{$P_{\text {exp }}$} & \multicolumn{1}{c}{$P_{\text {cal }}$} & \multicolumn{1}{c}{$P_{\text {exp }}$} & \multicolumn{1}{c}{$P_{\text {cal }}$} \\
\hline${ }^{4} I_{15 / 2}$ & 36.74 & 25.42 & - & - \\
${ }^{4} F_{3 / 2}$ & 402.49 & 335.16 & 244.30 & 316.73 \\
${ }^{4} F_{5 / 2},{ }^{2} H_{9 / 2}$ & 890.55 & 936.52 & 753.34 & 829.53 \\
${ }^{4} F_{7 / 2},{ }^{4} S_{3 / 2}$ & 824.34 & 863.84 & 783.19 & 762.94 \\
${ }^{4} F_{9 / 2}$ & 78.73 & 73.91 & 62.35 & 63.95 \\
${ }^{2} H_{11 / 2}$ & 19.43 & 19.99 & 16.71 & 20.09 \\
${ }^{4} G_{5 / 2},{ }^{2} G_{7 / 2}$ & 7220.92 & 7239.54 & 3885.63 & 3895.74 \\
${ }^{2} K_{13 / 2},{ }^{4} G_{7 / 2},{ }^{4} G_{9 / 2}$ & 1375.88 & 1118.80 & 969.25 & 828.91 \\
${ }^{2} K_{15 / 2},{ }^{2} G_{9 / 2}$, & & & & \\
$\left({ }^{2} D,{ }^{2} F\right)_{3 / 2},{ }^{4} G_{11 / 2}$ & 300.70 & 175.72 & 198.55 & 157.10 \\
${ }^{2} P_{1 / 2},{ }^{2} D_{5 / 2}$ & 93.09 & 95.77 & 66.04 & 91.01 \\
${ }^{4} D_{3 / 2},{ }^{4} D_{5 / 2},{ }^{2} I_{11 / 2}$, & & & & \\
${ }^{4} D_{1 / 2},{ }^{2} L_{15 / 2}$ & 1789.67 & 1854.67 & 1730.68 & 1736.62 \\
\hline \multicolumn{4}{c}{$\mathrm{KNd}\left(\mathrm{MoO}_{4}\right)_{2}$} & \multicolumn{3}{|c}{$\mathrm{KNd}(\mathrm{WO})_{4}$} \\
\hline
\end{tabular}

in excitation spectra of europium single crystals. Two questions need reply: (a) why are differences in intensities of vibronic components observed in excitation and emission spectra and (b) what is the change of intensities of vibronic sidebands in lanthanide molybdates and tungstates. Table II compiles both the Stark components of electronic lines and energies of vibration modes composed of them. The vibronic lines were assigned on the basis of IR and Raman data [10]. Only those lines are listed which are repeated in the absorption and excitation spectra of neodymium and europium compounds.

According to Blasse's considerations, the differences in intensities of vibronic sidebands in excitation and emission spectra can be given both by the values of matrix elements of $\left\|U^{(2)}\right\|$ tensor operator for different electronic transition $\left({ }^{5} D_{0,2}\right.$ and $\left.{ }^{7} F_{0,2}\right)$ and by an appropriate energy domi-nators $\Delta$ included in relevant closure relation of Judd [16]. The change in intensities of vibronic components in neodymium molybdate and tungstate could be considered on the basis of theoretical model. Indeed, the change in polarizability of oxygen atoms involved in different clathrates and free $\mathrm{MO}_{4}^{2-}$ polyhedra can follow the intensity variation. An additional effect can be widening of the region of external vibration modes in IR spectra, providing probably better conditions for electron-phonon coupling with respect to the gap between the Stark components of electronic lines. 
TABLE II

Stark components of electronic lines and energies of vibration modes composed of them for $\mathrm{KNd}\left(\mathrm{WO}_{4}\right)_{2}$ and $\mathrm{KNd}\left(\mathrm{MoO}_{4}\right)_{2}$ crystals at $5 \mathrm{~K}$.

\begin{tabular}{|c|c|c|c|c|c|c|c|}
\hline \multicolumn{4}{|c|}{$\mathrm{KNd}\left(\mathrm{WO}_{4}\right)_{2}$} & \multicolumn{4}{|c|}{$\mathrm{KNd}\left(\mathrm{MoO}_{4}\right)_{2}$} \\
\hline $\begin{array}{c}\text { Energy } \\
\text { level } \\
\nu\left[\mathrm{cm}^{-1}\right] \\
\end{array}$ & $\begin{array}{c}\text { Stark } \\
\text { comp. } \\
\nu_{0}\left[\mathrm{~cm}^{-1}\right] \\
\end{array}$ & $\begin{array}{l}\Delta \nu= \\
\nu-\nu_{0}\end{array}$ & $\begin{array}{c}\text { Assignm. to } \\
\text { resp. normal } \\
\text { modes }\end{array}$ & $\begin{array}{c}\text { Energy } \\
\text { level } \\
\nu\left[\mathrm{cm}^{-1}\right]\end{array}$ & $\begin{array}{c}\text { Stark } \\
\text { comp. } \\
\nu_{0}\left[\mathrm{~cm}^{-1}\right]\end{array}$ & $\begin{array}{l}\Delta \nu= \\
\nu-\nu_{0}\end{array}$ & $\begin{array}{l}\text { Assignm. to } \\
\text { resp. normal } \\
\text { modes }\end{array}$ \\
\hline \multicolumn{8}{|c|}{${ }^{4} I_{9 / 2} \rightarrow{ }^{4} G_{5 / 2},{ }^{2} G_{7 / 2}$} \\
\hline 17877 & 17520 & 357 & $\delta\left(\mathrm{WO}_{n}\right)$ & 18164 & 17428 & 736 & $\nu_{\text {as }}\left(\mathrm{MoO}_{4}\right)$ \\
\hline 17935 & 17520 & 415 & $\delta\left(\mathrm{WO}_{n}\right)$ & 18194 & 17428 & 766 & $\nu_{\text {as }}\left(\mathrm{MoO}_{4}\right)$ \\
\hline 18193 & 17520 & 673 & $\nu_{\mathrm{as}}\left(\mathrm{W}<\mathrm{O}^{\mathrm{O}}>\mathrm{W}\right)$ & 18281 & 17428 & 853 & $\nu_{\text {as }}\left(\mathrm{MoO}_{4}\right)$ \\
\hline 18255 & 17520 & 735 & $\nu_{\mathrm{s}}\left(\mathrm{W}<\mathrm{O}_{\mathrm{O}}>\mathrm{W}\right)$ & & & & \\
\hline & & & & 17909 & 17183 & 726 & $\nu_{\text {as }}\left(\mathrm{MoO}_{4}\right)$ \\
\hline 17877 & 17241 & 636 & $\nu_{\mathrm{as}}(\mathrm{W}<$ & 17956 & 17183 & 773 & $\nu_{\mathrm{as}}\left(\mathrm{MoO}_{4}\right)$ \\
\hline 17963 & 17241 & 722 & $\nu_{\mathrm{as}}(\mathrm{W}<\mathrm{O}>\mathrm{W})$ & 18096 & 17183 & 913 & $\nu_{\mathrm{s}}\left(\mathrm{MoO}_{4}\right)$ \\
\hline 18025 & 17241 & 783 & $\nu_{s}\left(\mathrm{~W}<\mathrm{O}_{\mathrm{O}}^{\mathrm{O}}>\mathrm{W}\right)$ & & & & \\
\hline & & & & 17772 & 17027 & 745 & $\nu_{\text {as }}\left(\mathrm{MoO}_{4}\right)$ \\
\hline 17617 & 16949 & 668 & $\nu_{\mathrm{as}}\left(\mathrm{W}<{ }_{\mathrm{O}}^{\mathrm{O}}>\mathrm{W}\right)$ & 17844 & 17027 & 817 & $\nu_{\text {as }}\left(\mathrm{MoO}_{4}\right)$ \\
\hline 17877 & 16949 & 928 & $\nu(\mathrm{W}=0)$ & 17956 & 17027 & 929 & $\nu_{\mathrm{s}}\left(\mathrm{MoO}_{4}\right)$ \\
\hline \multicolumn{8}{|c|}{${ }^{4} I_{9 / 2} \rightarrow{ }^{4} F_{5 / 2},{ }^{2} H_{9 / 2}$} \\
\hline 13035 & 12839 & 196 & $T^{\prime}\left(\mathrm{Ln}^{3+}\right)$ & 12844 & 12724 & 120 & $T^{\prime}\left(\mathrm{Mo}^{6+}\right)$ \\
\hline 13237 & 12839 & 398 & $\delta\left(\mathrm{WO}_{n}\right)$ & 13133 & 12724 & 409 & $\delta\left(\mathrm{MoO}_{4}\right)$ \\
\hline 13243 & 12839 & 404 & $\delta\left(\mathrm{WO}_{n}\right)$ & 12763 & 12381 & 382 & $\delta\left(\mathrm{MoO}_{4}\right)$ \\
\hline 13080 & 12739 & 341 & $\delta\left(\mathrm{WO}_{n}\right)$ & 13133 & 12381 & 752 & $\nu_{\mathrm{as}}\left(\mathrm{MoO}_{4}\right)$ \\
\hline 13204 & 12739 & 465 & $\nu_{\mathrm{s}}($ WOW $)$ & 13268 & 12381 & 887 & $\nu_{\mathrm{as}}\left(\mathrm{MoO}_{4}\right)$ \\
\hline 13204 & 12571 & 633 & $\nu_{\mathrm{as}}(\mathrm{W}<\mathrm{O}>\mathrm{W})$ & & & & \\
\hline 13237 & 12571 & 666 & $\nu_{\text {as }}\left(\mathrm{W}<{ }_{\mathrm{O}}^{\mathrm{O}}>\mathrm{W}\right)$ & & & & \\
\hline 12788 & 12385 & 403 & $\delta\left(\mathrm{WO}_{n}\right)$ & & & & \\
\hline 12801 & 12385 & 416 & $\delta\left(\mathrm{WO}_{n}\right)$ & & & & \\
\hline 13204 & 12385 & 819 & $\nu_{s}(\mathrm{~W}<\mathrm{O}>\mathrm{W})$ & & & & \\
\hline 13243 & 12385 & 858 & $\nu_{\mathrm{s}}\left(\mathrm{W}<\mathrm{O}_{\mathrm{O}}^{\mathrm{O}}>\mathrm{W}\right)$ & & & & \\
\hline
\end{tabular}

\section{References}

[1] M. Buijs, G. Blasse, L.H. Brixner, Phys. Rev. B 34, 12 (1986).

[2] P.A.M. Berdowski, G. Blasse, J. Lumin. 29, 243 (1984).

[3] J.P.M. van Vliet, D. van der Voot, G. Blasse, J. Lumin. 42, 305 (1989).

[4] A.A. Kaminskii, Laser Crystals, Springer, Berlin 1981, and references therein. 
[5] N. Yamada, S. Shionoya, J. Phys. Soc. Jpn. 31, 3 (1971).

[6] G. Blasse, Inorg. Chim. Acta 167, 33 (1990).

[7] M.P. Hehlen, H. Riesen, H.U. Güdel, Inorg. Chem. 30, 2273 (1991).

[8] R.F. Klevtsova, L.P. Kozeeva, P.V. Klevtsov, Kristallografiya 19, 89 (1974).

[9] J. Legendziewicz, Bull. Pol. Acad. Sci. Chem. 33, 147 (1985), and references therein.

[10] L. Macalik, Ph.D. Thesis, Polish Academy of Sciences, Wrocław 1991.

[11] R.F. Klevtsova, L.M. Volkova, Kristallografiya 17, 4 (1972).

[12] J. Hanuza, L. Macalik, Spectrochim. Acta A 43, 3 (1987).

[13] J. Legendziewicz, in: Excited States of Transition Elements, Eds. W. Stręk, W. Ryba-Romanowski, J. Legendziewicz, B. Jeżowska-Trzebiatowska World Sci., Singapore 1991, p. 149, and references therein.

[14] S.F. Mason, R.D. Peacock, B. Steward, Mol. Phys. 30, 1829 (1975).

[15] W.T. Carnall, S. Siegel, J.R. Ferraro, B. Tani, E. Gebert, Inorg. Chem. 12, 560 (1973).

[16] B.R. Judd, Phys. Scr. 21, 543 (1980). 